\title{
A EDUCAÇÃO AMBIENTAL NA FORMAÇÃO INICIAL DE PROFESSORES DE BIOLOGIA: CONCEPÇÕES, COMPONENTES CURRICULARES E POSSIBILIDADES DE AÇÕES SEGUNDO OS LICENCIANDOS
}

\section{ENVIRONMENTAL EDUCATION IN TEACHER TRAINING OF BIOLOGY: CONCEPTS, CURRICULUM COMPONENTS AND POSSIBILITIES FOR ACTIONS BY UNDERGRADUATES}

\author{
Melissa Reis ${ }^{1}$, Nathan da Matta Oliveira ${ }^{2}$, Raiele do Valle Perlingeiro ${ }^{3}$ e Tatiana Galieta $^{4}$ \\ ${ }^{1}$ Licencianda em Ciências Biológicas - Departamento de Ciências - Faculdade de Formação de \\ Professores (FFP)/Universidade do Estado do Rio de Janeiro (UERJ). melissa.biologia2012@ gmail.com \\ ${ }^{2,3}$ Licenciandos em Ciências Biológicas - Departamento de Ciências - FFP/UERJ. Bolsistas \\ CETREINA/UERJ.nnathan_matta_@hotmail.com; raiele@ hotmail.com \\ ${ }^{4}$ Professora Adjunta do Departamento de Ciências - Programa de Pós-Graduação em Ensino de Ciências, \\ Ambiente e Sociedade - FFP/UERJ. tatigalieta@gmail.com
}

\begin{abstract}
RESUMO
O presente artigo relata uma pesquisa realizada com alunos de um curso de licenciatura em Biologia cujo objetivo geral consistiu na investigação das concepções de Educação Ambiental (EA) que esses licenciandos possuem buscando relacioná-las à formação acadêmica propiciada nas diferentes disciplinas que compõem o currículo do curso. A metodologia empregada foi de natureza quantiqualitativa e o instrumento de coleta de dados consistiu em um questionário com questões fechadas e abertas. Os resultados da análise dos 104 questionários respondidos apontam para a predominância de concepções de EA dos tipos integradora e de resolução de problemas. Com relação aos componentes curriculares, os licenciandos identificaram Ecologia e Laboratório de Ensino como as disciplinas obrigatórias fundamentais para o estudo da EA. Finalmente, eles consideram-se aptos não só a trabalharem com temas ambientais como também levariam em conta o conhecimento do entorno social escolar em suas aulas sobre EA em suas futuras ações como professores.
\end{abstract}

Palavras-chave: educação ambiental, formação inicial de professores, ensino de biologia.

\begin{abstract}
This article reports on a survey conducted with students of a degree in Biology whose general objective was to investigate the concepts of environmental education (EE) those seeking undergraduates have to relate them to academic training afforded in the different disciplines that make up the curriculum course. The methodology employed presented quantitative and qualitative aspects and the data collection instrument consisted of a questionnaire with closed and open questions. The results of the analysis of 104 questionnaires point to the predominance of conceptions of EA types of integrative and problem-solving. Regarding the curriculum components, the students consider Ecology and Teaching Laboratory are compulsory subjects for addressing fundamental issues of EE. Finally, they consider themselves capable not only to work with environmental issues but also would take into account the knowledge of the social environment in their school classes on EE in their future actions as teachers.
\end{abstract}

Key words: Environmental Education, teacher training, Biology teaching. 


\section{Introdução}

Atualmente, ainda são tímidas iniciativas que inserem a Educação Ambiental (EA) em contextos educativos formais desde o estabelecimento da Política Nacional de Educação Ambiental (PNEA) em 2002 ${ }^{1}$. Práticas de Educação Ambiental têm sido sugeridas e realizadas, em maior ou menor amplitude, nas escolas de nosso país e, consequentemente, não podemos deixar de considerar o viés ideológico que subsidiam tais ações, algo que tem sido foco de análises de pesquisadores do campo da Educação Ambiental filiados a uma vertente crítica e transformadora (LOUREIRO e COSSÍO, 2007). Percebemos que, apesar da EA ter entrada na escola via projetos de empresas privadas, de organizações não governamentais e de iniciativas isoladas dos professores, na maioria das escolas a EA é efetivada devido à iniciativa de organização e execução de projetos pela mobilização de grupos de professores (TRAJBER e MENDONÇA, 2006).

Esse dado relevante acaba por levar-nos à necessidade de conhecer aspectos relacionados à formação inicial dos professores uma vez que eles se constituem nos principais formadores em temas de EA nos espaços formais de educação. Além disso, é importante ressaltar que a PNEA, em seu Art. 11, estabelece que "a dimensão ambiental deve constar dos currículos de formação de professores, em todos os níveis e em todas as disciplinas” (BRASIL, 1999). Desta forma, espera-se que os cursos de licenciatura, sobretudo aqueles que compõem a área de Ciências da Natureza, criem espaços para a discussão de temas ambientais já que futuras práticas escolares relacionadas à EA podem vir a ser direta e indiretamente afetadas pelas experiências vivenciadas nessa etapa da formação docente.

Nesse sentido, alguns autores têm investigado as concepções de EA de futuros professores de ciências com diferentes objetivos, dentre os quais destacamos os trabalhos de Giubbina e cols. (2008), Verona e Lorencini Jr. (2009) e Silva e Carvalho (2012) que focalizam a formação de professores de ciências naturais. Giubbina e cols. (2008) mostram que futuros professores de Química percebem que esta formação não se encontra restrita às disciplinas mas também ocorre em atividades extracurriculares. As autoras destacam o fato de que para "os licenciandos, embora a temática ambiental seja discutida em várias disciplinas ao longo do Curso, a abordagem é periférica e

\footnotetext{
${ }^{1}$ O Decreto n $^{\text {o }} 4.281$ de 25/06/2002 regulamentou a Lei $n^{\circ}$ 9.795, de 27/04/1999, estabelecendo a PNEA que, entre outros pontos, qualifica a educação ambiental como componente essencial e permanente da educação nacional, tendo como âmbitos de ação a educação formal e não formal (LIPAI et al., 2007).
} 
superficial, não considerando aspectos socioambientais" (GIUBINNA et al., op. cit., p. 9). Em um curso de licenciatura em Ciências Biológicas, Verona e Lorencini Jr. (2009) avaliam as concepções de EA dos futuros professores considerando que essas contribuem para a compreensão das práticas educacionais que serão desenvolvidas por eles. Seus resultados revelam que, apesar dos alunos considerarem "a temática ambiental como um componente essencial no currículo do Ensino Fundamental e Médio", eles declaram "não estarem preparados para trabalhar com esses assuntos na educação básica ao final da graduação, pois consideram que a EA praticamente não foi abordada ao longo do curso" (VERONA e LORENCINI JR., op. cit., p. 192). Outra conclusão interessante do estudo diz respeito ao predomínio de uma concepção abrangente de EA, tida como "uma visão integradora, também relacionada à transformação social e à resolução de problema”. Como no trabalho citado anteriormente, estes autores atribuem esse resultado, entre outros fatores, “às interações sociais estabelecidas por esses alunos, à participação em projetos extraclasse (pesquisa ou extensão) e ao próprio interesse pessoal em relação à temática em questão" (VERONA e LORENCINI JR., idem). Já no contexto de formação de professores de Física, Silva e Carvalho (2012) apontam que as concepções destes sobre a questão ambiental podem vir a se tornar obstáculos para a incorporação de abordagens mais complexas das relações entre ciência-tecnologia-sociedade-ambiente em suas práticas de ensino não rompendo com o modelo de conhecimento científico factual e conceitual. Eles concluem que os licenciandos não possuem "um entendimento mais amplo do significado da temática ambiental" e, além disso, que "a problemática ambiental é vista, pelos licenciandos em Física, como um tema voltado exclusivamente aos especialistas de algumas áreas específicas do conhecimento, como, por exemplo, a Biologia" (SILVA e CARVALHO, op. cit., p. 381).

No que diz respeito às reflexões acerca das ações concretas de mudança nos cursos de licenciatura encontramos algumas revisões bibliográficas que têm mostrado a preocupação em buscar pistas na literatura do campo da EA sobre como a comunidade acadêmica tem pensado a formação de professores/educadores ambientais. A pesquisa de Guimarães e Alves (2012), por exemplo, chama-nos a atenção ao concluir que os pesquisadores estão de fato preocupados em realizar críticas à EA reducionista, como possibilidade de superação do paradigma de EA vigente (“orientado por uma subjetividade capitalística e marcado por profundas desigualdades sociais", p. 57) a partir de experiências mediadas pela pesquisa-ação, além de incorporar discussões 
acerca dos desafios na operacionalização da legislação que institui a EA. As autoras consideram que "tal inquietação [por parte dos pesquisadores] se deve, principalmente, porque um professor mal formado dificilmente se torna capaz de abordar a EA de forma profícua com seus estudantes, os quais, por sua vez, perdem a oportunidade de entrar em contato com um conhecimento reflexivo e transformador" (GUIMARÃES e ALVES, 2012, p. 64).

Baseados na leitura dos trabalhos citados acima e motivados pelo estudo do histórico do campo da Educação Ambiental e de algumas práticas efetivadas em escolas que se deu no âmbito da disciplina Laboratório de Ensino I do curso de Ciências Biológicas, Faculdade de Formação de Professores (FFP) da Universidade do Estado do Rio de Janeiro (UERJ), os autores deste trabalho iniciaram um grupo de estudos no qual foram discutidos aspectos relacionados à formação docente e sua futura atuação no magistério especificamente em temas ambientais. Surgiu, assim, o interesse pelo conhecimento de nossa própria realidade, do contexto no qual os licenciandos recémingressos no referido curso se deparariam ao longo de sua formação acadêmica, bem como das concepções de EA que seus colegas de curso de semestres mais avançados apresentavam.

É situado neste cenário que o se insere o presente artigo que apresenta os resultados de um estudo que investiga as concepções de EA que os licenciandos em Ciências Biológicas da FFP/UERJ possuem buscando relacioná-las à formação acadêmica propiciada nas diferentes disciplinas que compõem o currículo do curso. Tal estudo desdobrou-se nos seguintes objetivos específicos: (i) reconhecer as concepções de EA que os licenciandos apresentam; (ii) identificar as disciplinas do currículo do referido curso que eles relacionam à EA; (iii) compreender aspectos relativos à EA envolvidos em sua futura ação no magistério. Para alcançarmos esses objetivos elaboramos um método de coleta de dados (questionário) que nos permitiu acessar dados tanto quantitativos quanto qualitativos relativos aos sujeitos da pesquisa, o qual é descrito a seguir.

\section{Metodologia}

Para identificarmos as concepções que os licenciandos do curso de Ciências Biológicas da FFP/UERJ possuem com relação à EA, organizamos um questionário com sete questões, sendo cinco fechadas e duas abertas. Tanto para a elaboração do questionário como para a análise dos resultados baseamo-nos nos trabalhos citados 
anteriormente e, mais especificamente, nas categorias propostas por Cunha e cols. (2006) e Verona e Lorencini Jr. (2009). Do trabalho de Cunha e cols. (2006) utilizamos as categorias de classificação das concepções de futuros professores, a saber: tradicional, antropocêntrica, resolução de problemas e integradora. As categorias, bem como as frases retiradas do trabalho de Verona e Lorencini Jr. (2009), foram empregadas na $2^{\mathrm{a}}$ questão. Os dados obtidos permitiram-nos proceder a uma análise quantitativa e qualitativa.

O questionário foi concebido em torno de três blocos centrais de perguntas; o primeiro que focalizava as concepções sobre EA dos licenciandos (questões 1 a 3), o segundo que explorava as disciplinas do curso de licenciatura que contemplam aspectos ambientais de acordo com os alunos (questões 4 e 5) e o terceiro bloco no qual eles poderiam avaliar sua formação e futura ação como professores de temas ambientais (questões 6 e 7).

O questionário foi respondido por um total de 104 alunos, distribuídos entre o $2^{\circ}$ e $7^{\circ}$ período (exceto o $3^{\circ}$ período cuja turma não foi encontrada disponibilidade de horário comum para a coleta dos dados). A dinâmica estabelecida para a obtenção das respostas foi a seguinte: os autores estabeleceram contato prévio com os professores responsáveis por cada disciplina obrigatória dos referidos períodos, os quais estabeleciam os melhores horários para que os questionários fossem passados. Os alunos recebiam, então, os questionários sem qualquer tipo de orientação e apenas eram informados sobre sua finalidade. Alguns alunos optaram por não responder $o$ questionário (foram devolvidos em branco) e outros responderam de forma incorreta algumas questões. Nestes dois casos, as respostas foram desconsideradas. É importante ressaltar que não tivemos a intenção de obter uma amostra representativa, tanto que sequer recorremos a testes estatísticos para obtermos o número mínimo de questionários a serem obtidos, uma vez que consideramos o estudo como exploratório ${ }^{2}$. Apesar dos resultados quantitativos serem apresentados, sobretudo na forma de gráficos, a pesquisa também possui um caráter qualitativo na análise dos dados uma vez que busca a interpretação dos mesmos.

\footnotetext{
${ }^{2}$ No semestre anterior à coleta de dados, pelo levantamento realizado pela secretaria do Departamento de Ciências, 277 alunos estavam regularmente matriculados no curso. Assim, considerando este universo populacional temos uma amostra de $37,5 \%$ a qual pode ser estimada como sendo representativa da população.
} 
A análise dos resultados pauta-se em uma visão crítica de EA com a qual nos identificamos e acreditamos ser congruente com nossa filosofia educacional segundo a qual educar é um ato político que visa à transformação e libertação do educando de uma situação opressora (FREIRE, 1987). De acordo com Loureiro (2012), a EA crítica visa à promoção simultânea da(o): participação ativa das pessoas e grupos na melhoria do ambiente; autonomia dos grupos sociais na construção de alternativas sustentáveis; amplo direito à informação como condição para a tomada de decisão; mudança de atitudes; aquisição de habilidades específicas; problematização da realidade ambiental.

A vertente crítica de EA pretende superar a visão conservacionista que é característica das primeiras atividades de EA no Brasil as quais se configuravam como "um instrumento técnico-científico voltado para a resolução de problemas ambientais por meio da transmissão de conhecimentos ecológicos e da sensibilização" (LOUREIRO, 2012, p. 82). No entanto, não podemos deixar de reconhecer que, ainda hoje, encontramos vertentes de EA que vão desde aquela visão pautada na ideia de transmissão de conhecimentos para o "doutrinamento" de comportamento, passando por tendências intermediárias, até uma visão crítica e transformadora. Acreditamos que isso esteja relacionado à própria constituição do campo da EA ainda recente no Brasil (cerca de apenas 30 anos). Sem dúvidas, que essa tendência pode ser encontrada nos discursos de educadores de diferentes níveis e de futuros professores.

\section{Resultados e Discussão}

Os resultados obtidos a partir das respostas aos questionários serão divididos de acordo com os três blocos de perguntas descritas anteriormente. Assim, iniciamos a apresentação dos resultados que se referem às concepções de EA dos licenciandos.

\section{1) Concepções de Educação Ambiental}

A primeira questão foi apresentada da seguinte forma:

1) Ao pensar em "Educação Ambiental" que termo lhe parece mais adequado para defini-la? (Marque apenas uma opção!)
( ) preservação
( ) conscientização
( ) mudança de atitudes
( ) questões socioeconômicas
( ) conservação
( ) sustentabilidade

Por ser ainda um campo recente e em constituição, a EA tem sido concebida por seus pesquisadores a partir de concepções diversificadas de ambiente, estabelecendo em maior ou menor grau diálogos com outras áreas do conhecimento. Desta forma, a própria concepção de EA pode ser compreendida desde uma visão mais restrita - ainda 
vinculada à ideia conservacionista e preservacionista - até uma concepção mais crítica que busca considerar aspectos sociais e políticos. Ao observarmos o Gráfico 1 percebemos que poucos licenciandos apresentam uma visão conservacionista e tampouco relacionam a EA a questões socioeconômicas, tendo sido o termo “conscientização" o mais utilizado para definir a EA (64\%).

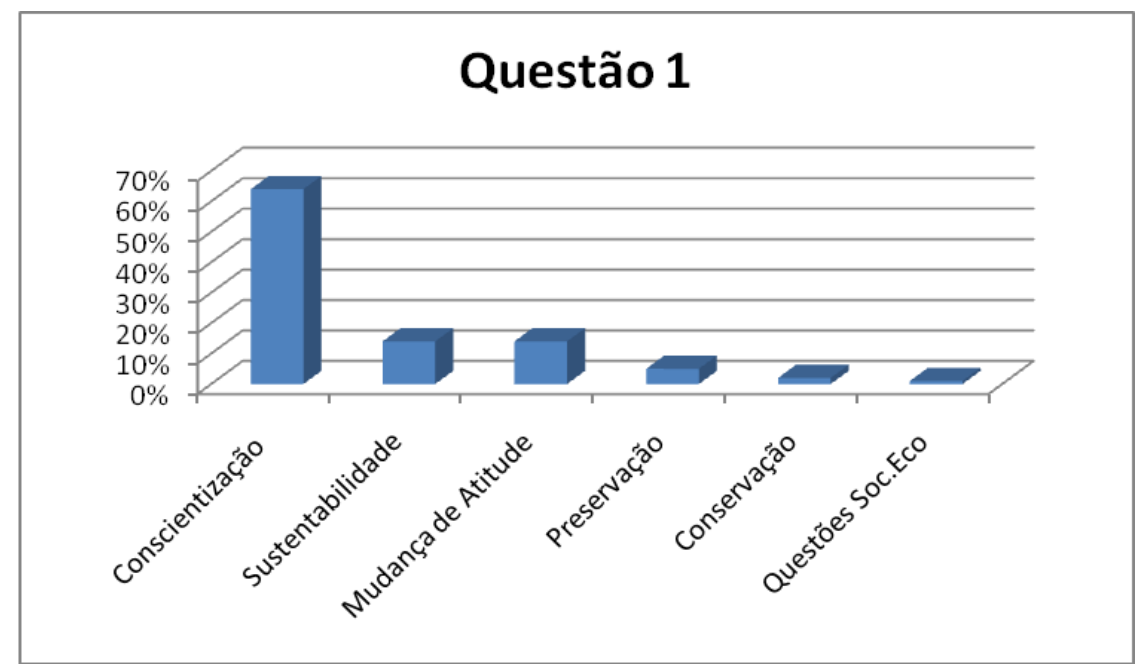

Gráfico 1: percentual de respostas obtidas na questão 1.

É interessante notar que o conceito de conscientização nasce nas obras de Paulo Freire e é apropriado por vertentes críticas de EA. Aqui, considera-se que o processo de tomada de consciência pelo sujeito apenas assume uma perspectiva de conscientização crítica (e não ingênua) quando o mesmo é capaz de (re)conhecer a causalidade dos fenômenos sociais e da historicidade de suas ações possibilitando-o construir sua autonomia (FREIRE, 1979). Apesar de encontrarmos um valor expressivo desta resposta, não podemos afirmar que os alunos que assinalaram esta opção de fato possuem o conceito de conscientização conforme descrito acima, daí a importância de aprofundarmos essa questão em futuras entrevistas. Vale ainda ressaltar que as demais opções tiveram resultados equilibrados: sustentabilidade e mudança de atitude (14\% cada), opções que podem ser relacionadas a um discurso mais tradicional da EA. Além disso, foram ainda obtidos $5 \%$ das respostas para preservação e apenas $1 \%$ para questões socioeconômicas.

Na Questão 2, apoiamo-nos nas categorias estabelecidas por Cunha e cols. (2006) para tentarmos nos aproximar das concepções de EA dos licenciandos. Foram apresentadas frases retiradas do trabalho de Verona e Lorencini Jr. (2009) que representavam quatro tipos de concepções as quais foram ordenadas (aleatoriamente) no 
questionário da seguinte forma: A) Integradora; B) Transformação Social; C) Tradicional; D) Resolução de Problemas, conforme o texto a seguir:

2) Assinale com um $X$ o item abaixo que você considera como sendo aquele que melhor representa sua visão de Educação Ambiental (EA):

( ) "A questão ambiental abrange toda a complexidade da ação humana, desse modo para não atribuir à EA um caráter reducionista, é necessário que se aborde temas que vão desde questões sociais até a conservação do meio ambiente."

( ) "O que realmente importa dentro de um programa de EA é que as comunidades se organizem e façam dessa organização a sua força de luta na busca de condições dignas de vida. Essa ação deve significar uma autorreflexão promovida junto à comunidade, que leve à aquisição de uma consciência crítica de sua realidade."

( ) "A questão ecológica ou ambiental deve-se restringir à preservação dos ambientes naturais e o combate à poluição. É preciso, portanto, estabelecer o campo do saber ambiental, e relacioná-lo diretamente com EA. Caso contrário, ao querer transformar tudo em EA, estaríamos submetendo-a a banalização."

( ) "A EA deve enfatizar a ação, deve estar vinculada a atividades práticas, voltadas para problemas concretos, como coleta seletiva de lixo, plantio de árvores, entre outros. Sendo assim, a EA vista como necessária na busca de soluções para os problemas ambientais, acaba por despertar no cidadão a necessidade do compromisso com a natureza, no sentido de utilizá-la de forma racional."

As respostas obtidas são apresentadas no Gráfico 2.

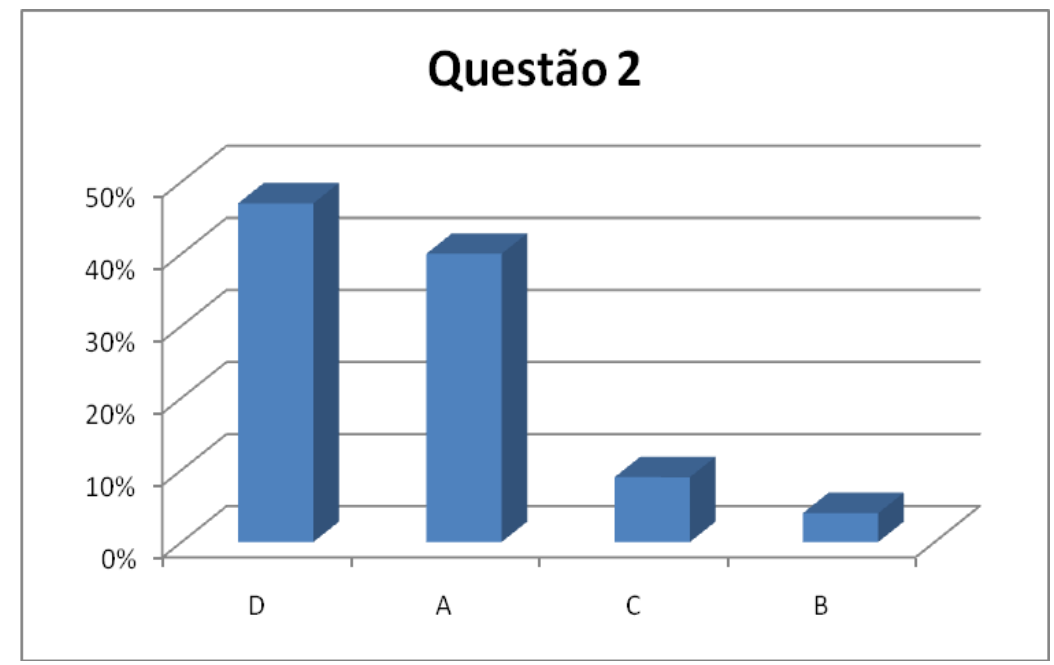

Gráfico 2: percentual de respostas obtidas na Questão 2.

Observamos um equilíbrio entre as concepções denominadas "resolução de problemas" (47\%) e “integradora" (40\%). Estes resultados estão em sintonia com aqueles encontrados por Verona e Lorencini Jr. (2009) em sua pesquisa com licenciandos da Universidade Estadual de Londrina. De acordo com Cunha e cols. (2006), pessoas que apresentam a concepção "resolução de problemas" associam a EA à "utilização racional do meio ambiente levando em conta aspectos de desenvolvimento 
sustentável e gestão ambiental” (CUNHA et al., 2006, p. 30). Enquanto que os filiados à concepção "integradora" possuem um "entendimento mais global da questão ambiental" uma vez que concebem "relações dinâmicas entre aspectos naturais, sociais e culturais" (idem). É interessante notar que ao apresentarmos frases que poderiam definir sua concepção de EA, quase metade dos alunos optou por uma visão que se encontra em sintonia com o discurso de desenvolvimento sustentável tão presente na mídia e que supera os $14 \%$ obtidos na primeira questão para a opção "sustentabilidade". A segunda colocação para a concepção "integradora" permite-nos inferir que os licenciandos não associam a EA apenas à conservação considerando também o meio sociocultural que constitui (e é constituído) o (pelo) ambiente. As concepções "tradicional” e "transformação social" apresentaram $9 \%$ e $4 \%$ das respostas, respectivamente. A primeira está vinculada a uma visão antropocêntrica segundo a qual o homem assume uma relação utilitarista e preservacionista com a natureza. Já a segunda, apresenta um enfoque sócio-político-ambiental com uma "desterritorialização da EA".

A terceira questão foi colocada da seguinte forma:

3) Abaixo são apresentadas situações que podem ser consideradas problemáticas do ponto de vista ambiental. Numere, em ordem decrescente de importância, cada um desses fatores. (Atribuindo 1 para o mais importante e 6 para o menos importante.)
( ) poluição
( ) atuação do homem na natureza
( ) questões sociais e econômicas
( ) desmatamento
( ) falta de consciência ambiental
( ) escassez dos recursos naturais

Para classificarmos os resultados obtidos nessa questão foi contabilizado o total de votos nas seis opções em cada uma das posições (de 1 a 6 ). Assim, obtivemos a colocação predominante dentro de cada uma das opções. Por exemplo, a opção "falta de consciência ambiental" obteve o maior número de votos (39, do total de 103) na primeira colocação ficando, desta forma, no primeiro lugar geral (ver resultados totais na Tabela 1).

\begin{tabular}{|c|l|}
\hline Ordem de importância & \multicolumn{1}{c|}{ Situações problemáticas } \\
\hline $1^{\mathbf{o}}$ & Falta de consciência ambiental \\
\hline $2^{\mathbf{o}}$ & Atuação do homem na natureza \\
\hline $3^{\mathbf{o}}$ & Desmatamento \\
\hline $4^{\mathrm{o}}$ & Poluição \\
\hline $5^{\mathbf{o}}$ & Escassez dos recursos naturais \\
\hline $6^{\mathbf{o}}$ & Questões sociais e econômicas \\
\hline
\end{tabular}

Tabela 1: resultados da Questão 3. 
Quando temos "falta de consciência ambiental" como a primeira situação problemática do ponto de vista ambiental de acordo com os licenciandos estamos, de certa forma, corroborando os resultados que foram obtidos na primeira questão. Encontramos, novamente, forte relação entre o conceito de "conscientização" e EA para os sujeitos da pesquisa. No caso específico da terceira questão, não podemos afirmar qual a dimensão de consciência está sendo considerada pelos respondentes: se uma conscientização individual ou coletiva.

Apesar da opção "atuação do homem na natureza" remeter-se mais diretamente a uma visão antropocêntrica, de certa forma poderíamos compreender que as demais opções (desmatamento, poluição e escassez de recursos naturais) também estão relacionadas ao estilo de vida humana, sobretudo, em sociedades capitalistas, basicamente urbanas e industriais. Estas opções se remetem em última instância a questões sociais e econômicas as quais, segundo o nosso entendimento crítico de EA, situam-se na base das decisões políticas que afetam o modo de exploração dos recursos naturais e de consumo individual. Assim, entendemos que os resultados da terceira questão sinalizam a necessidade de contemplar nas disciplinas do currículo do curso de formação inicial discussões mais amplas que promovam o diálogo entre ambiente e aspectos de organização da sociedade.

\section{2) A Educação Ambiental no currículo da licenciatura}

O segundo bloco de questões tinha como intenção entender como os licenciandos percebem sua formação no curso buscando identificar as disciplinas nas quais a EA é abordada. A Questão 4 tinha o seguinte enunciado: “Cite, pelo menos, duas disciplinas obrigatórias do curso de licenciatura em Biologia que você considera fundamental a abordagem de temas de Educação Ambiental”. É importante ressaltar que eles não foram questionados sobre em quais disciplinas eles tiveram contato com a EA. As disciplinas mencionadas aparecem no Gráfico 3. 
Ensino, Saúde e Ambiente - V6 (3), pp. 96-113, dez. 2013

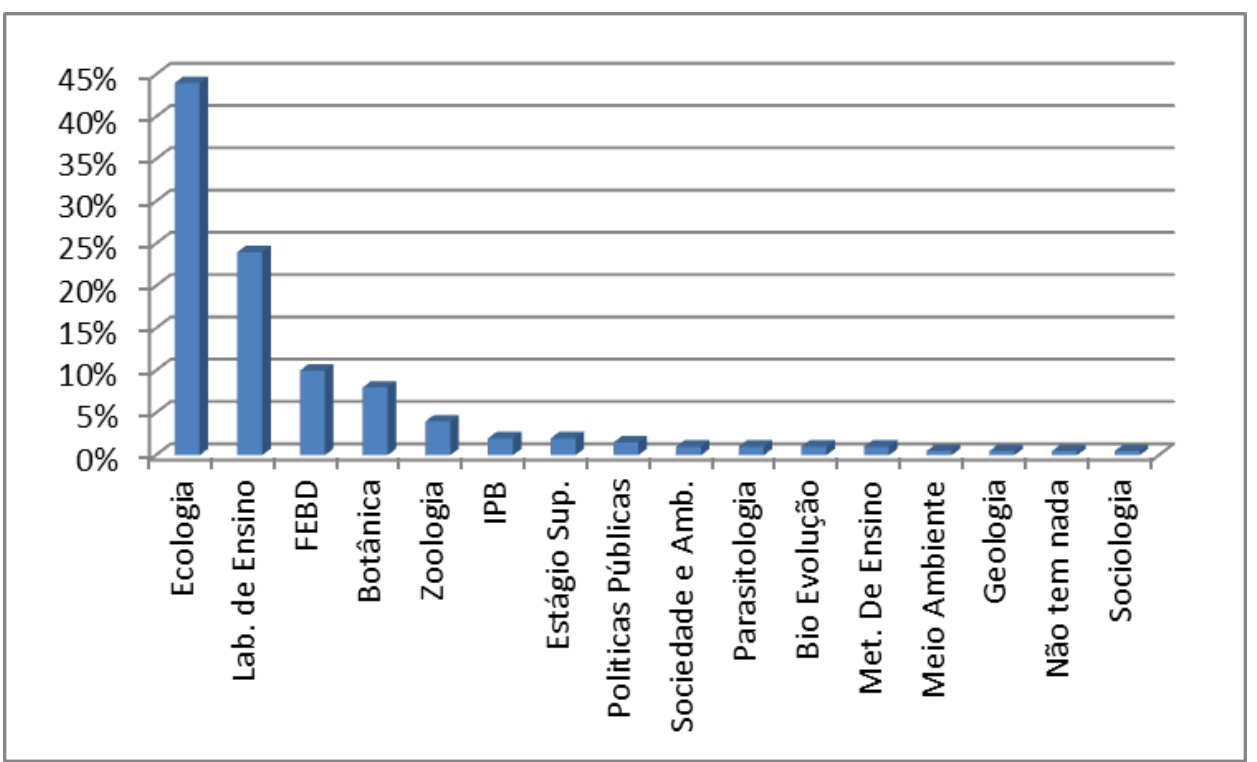

Gráfico 3: disciplinas elencadas pelos respondentes organizadas por percentual.

A disciplina Ecologia prevaleceu nas respostas, tendo sido mencionada por $44 \%$ dos respondentes. A segunda disciplina mais citada foi Laboratório de Ensino (24\%) e a terceira FEBD (Fundamentos para o Estudo da Biodiversidade) (10\%). Em seguida, aparecem Botânica e Zoologia com 8\% e 4\% das respostas, respectivamente. Foram ainda mencionadas disciplinas consideradas do núcleo pedagógico como IPB (Introdução ao Pensamento Biológico) (2\%), Estágio Supervisionado (2\%) e Metodologia do Ensino (1\%).

Acreditamos que o resultado encontrado, o qual situa na disciplina de Ecologia a "responsabilidade" pela abordagem de temas relacionados à EA, demonstra ainda uma visão de EA atrelada à necessidade de domínio de conhecimentos biológicos/ecológicos para o conhecimento do ambiente. Já a segunda colocação sendo ocupada pela disciplina Laboratório de Ensino ${ }^{3}$ pode sinalizar o entendimento dos licenciandos de que a questão ambiental também se encontra relacionada a aspectos propriamente pedagógicos segundo os quais o ambiente não pode ser pensado fora da esfera educacional mais ampla, bem como uma preocupação com o ensino da EA na escola visando uma futura atuação profissional.

\footnotetext{
${ }^{3} \mathrm{O}$ objetivo central das disciplinas "Laboratório de Ensino" (que perfazem o total de quatro ao longo do currículo e que são oferecidas desde o primeiro período) é entender determinados temas do ensino de ciências e biologia no contexto da escola básica e de espaços educativos não-formais a partir da produção de materiais e metodologias inovadoras para o trabalho com estes temas.
} 
Na Questão 5 perguntou-se: “Até o presente momento de sua licenciatura em Biologia quantas disciplinas abordaram temas relacionados à Educação Ambiental?”. Foram apresentadas as opções: 1 ou 2, 3 ou 4, mais de 5 ou nenhuma. O estrato mais votado foi o de 1 ou 2 disciplinas com quase 54\% do total de votos (ver Gráfico 4). Outros 35\% disseram já ter cursado três ou quatro disciplinas e apenas $8 \%$ assinalaram a opção "mais de 5" disciplinas e 3\% disseram que em nenhuma disciplina foram estudados temas de EA. Para análise desse último dado é importante ressaltar que alunos do $2^{\circ}$ período também responderam ao questionário. Desta forma, devemos levar em consideração que eles apenas teriam cursado as disciplinas obrigatórias presentes nesses dois primeiros períodos.

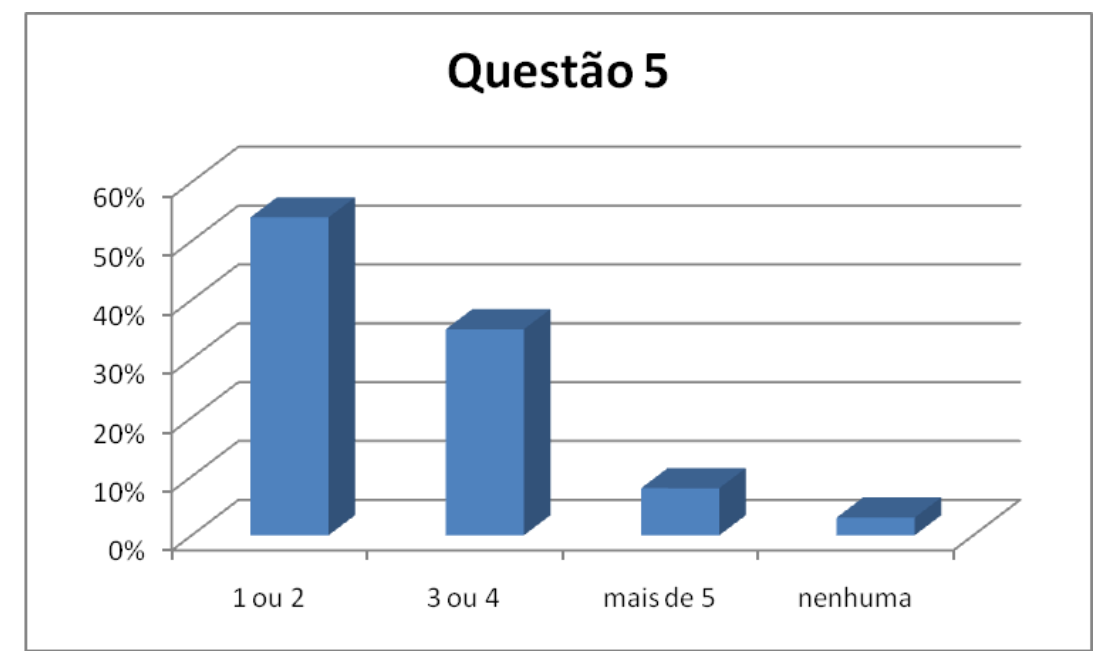

Gráfico 4: número de disciplinas já cursadas que abordaram temas de EA.

Os licenciandos reconhecem no currículo de seu curso pelo menos uma ou duas disciplinas que abordam temas de EA. Pretendemos aprofundar a análise dos dados obtidos nesta questão a partir da leitura das ementas das disciplinas obrigatórias e de entrevistas com os professores responsáveis por elas. No entanto, já podemos antecipar a existência de uma disciplina optativa de Educação Ambiental no referido currículo que não tem sido oferecida com frequência. Esta irregularidade, por outro lado, parece estar sendo "coberta" por outras disciplinas uma vez que a maioria absoluta dos alunos disse ter frequentado alguma disciplina que contemplou temas relacionados à EA.

3) Preparação para a atuação como professor de temas de EA na escola 
O último bloco de questões tinha como objetivo identificar os conhecimentos que os licenciandos consideram mais importantes em sua futura atuação no magistério, bem como perceber se os mesmos sentem-se preparados para abordar temas relacionados à EA na educação básica quando no papel de professores de ciências e biologia.

A Questão 6 perguntava: Que tipos de conhecimentos você considera como sendo mais importantes para sua atuação como futuro professor de Biologia no ensino de temas de Educação Ambiental? Numere em ordem decrescente de importância (onde 1 é o conhecimento mais importante). As opções oferecidas eram: conhecimentos pedagógicos, conhecimentos biológicos/ecológicos, conhecimentos sobre a situação ambiental da comunidade local, conhecimentos derivados de experiências anteriores em práticas de EA, conhecimentos sobre a realidade socioeconômica dos alunos.

Para classificarmos os resultados obtidos nessa questão foi contabilizado o total de votos nas cinco opções em cada uma das posições (de 1 a 5). Assim, obtivemos a colocação predominante dentro de cada uma das opções. Por exemplo, a opção “conhecimentos biológicos/ecológicos" obteve o maior número de votos $(53$, do total de 104) na primeira colocação ficando, desta forma, no primeiro lugar geral. A seguir apresentamos na Tabela 2 os resultados desta questão.

\begin{tabular}{|c|l|}
\hline Ordem de importância & \multicolumn{1}{|c|}{ Conhecimentos } \\
\hline $1^{\mathbf{o}}$ & Biológicos/Ecológicos \\
\hline $2^{\mathrm{o}}$ & Sobre a situação ambiental da comunidade local \\
\hline $3^{\mathrm{o}}$ & Derivados de experiências anteriores em práticas de EA \\
\hline $4^{\mathrm{o}}$ & Sobre a realidade socioeconômica dos alunos \\
\hline $5^{\mathrm{o}}$ & Pedagógicos \\
\hline
\end{tabular}

Tabela 2: resultados da questão 6 a partir de valores absolutos para cada opção.

Os resultados obtidos reforçam àqueles apresentados nas respostas da questão anterior segundo a qual as disciplinas de Ecologia seriam as principais responsáveis pelo ensino de temas de EA. A ideia de que o domínio de conteúdos da ciência de referência é o principal elemento para que práticas educacionais sejam bem sucedidas demonstra uma visão dicotomizada entre teoria e prática e, no caso específico da EA, que o simples conhecimento de conteúdos biológicos/ecológicos daria conta do ensino 
de temas de EA na escola. Tal dicotomia é ratificada quando observamos que os conhecimentos pedagógicos aparecem na última colocação na ordem de importância.

A segunda opção mais votada indica a preocupação dos futuros professores ao desenvolverem práticas de EA na escola em ter conhecimento acerca da situação ambiental da comunidade local. A realidade socioeconômica dos alunos, por outro lado, aparece na quarta posição. É interessante notar que os licenciandos atribuem valor a experiências anteriores em práticas de EA (dado também discutido por Giubbina e cols., 2008 e Verona e Lorencini Jr., 2009) indicando a importância que os mesmos atribuem aos diferentes contextos formativos vivenciados no decorrer do curso.

A sétima e última questão era aberta e trazia a seguinte pergunta: "Você acredita que ao final de seu curso de graduação, estará preparado para trabalhar a Educação Ambiental no Ensino Fundamental e Médio? Por quê?”. Para a primeira parte da questão obtivemos o seguinte resultado: $80 \%$ responderam que se sentem preparados, $11 \%$ disseram que não estão preparados, $8 \%$ oscilaram entre "talvez" e "não sei" e $1 \%$ não respondeu à questão.

Dentre as jusificativas mais frequentes dadas por aqueles que se consideram preparados para trabalhar temas de EA quando se tornarem professores, encontramos respostas em que os alunos justificam essa condição na qualidade do currículo do curso e na possibilidade de continuidade de sua formação a partir da busca por outros conhecimentos ao término da sua graduação. Destacamos como exemplos representativos de respostas positivas:

"Sim, a faculdade nos prepara em certos aspectos, porém a prática nos trará experiências novas que nos tornaram (sic) melhor educador."

"Sim. Pois durante todo o curso somos preparados para atuar com competência em todas as áreas."

Por outro lado, os licenciandos que não se consideram preparados para, ao final da graduação, ensinarem EA em suas futuras turmas justificaram essa resposta centrando em um principal argumento, a saber: o contato com a temática em poucas disciplinas do curso. Encontramos exemplos de respostas negativas semelhantes às reproduzidas abaixo:

"Não. Pois só estudei conteúdos de Educação ambiental em uma disciplina e acho que não foi o bastante para o meu conhecimento."

"Não. Poucas disciplinas com essas questões."

Os futuros professores, no entanto, nem sempre deixavam claro uma única 
postura com relação ao "sentir-se pronto" para a atuação docente no campo da EA no ensino formal. Observamos essa particularidade nas seguintes respostas:

"Sim, pois o trabalho deste tipo de tema requer um conhecimento ambiental da comunidade onde está sendo lecionado somado aos conhecimentos abordados na graduação."

"Não completamente, pois acredito que a realidade de cada local terá que gerar um estudo para que a Educação Ambiental possa realmente ser construída e concluída."

\section{Considerações Finais}

O presente trabalho apresentou uma análise das respostas de licenciandos do curso de Ciências Biológicas da FFP/UERJ a um questionário que visou reconhecer suas concepções de Educação Ambiental, bem como aspectos curriculares relacionados à sua formação inicial e à sua futura ação no magistério.

Os resultados às primeiras questões mostram que os alunos possuem concepções não tradicionais de EA. Ao serem questionados sobre o termo mais adequado para definir EA, a maioria escolheu a palavra "conscientização". Acreditamos que este resultado tanto pode sinalizar uma concepção crítica de EA segundo a qual a conscientização está relacionada a uma postura de transformação da realidade do entorno social do sujeito quanto a uma concepção conservacionista que pretende a simples mudança de comportamentos.

Com relação às concepções de EA, aproximadamente metade dos futuros professores escolheu a frase relacionada à concepção de "resolução de problemas", sendo a visão "integradora” a segunda colocada. De uma forma geral, este resultado pode nos indicar um avanço no que diz respeito às concepções ambientalistas conservacionistas tradicionais. No entanto, obtivemos um resultado aparentemente contraditório a este na terceira questão. Nela, as duas situações consideradas como sendo mais problemáticas do ponto de vista ambiental estão relacionadas a uma visão antropocêntrica (a falta de consciência ambiental e a atuação do homem na natureza), embora todas as demais alternativas estejam relacionadas de alguma forma aos impactos causados pela exploração dos recursos naturais pelo homem. Por outro lado, os resultados da terceira questão reforçam a importância do conceito de “conscientização/consciência ambiental". Desta forma, consideramos fundamental a 
segunda etapa da pesquisa que consistirá em entrevistas com alguns dos licenciandos respondentes ao questionário.

Os resultados das questões que focalizavam o currículo do curso mostram que, de acordo com os alunos, são poucas as disciplinas que abordam diretamente a EA. Os alunos identificam na Ecologia maior relação com o campo estando ainda disciplinas como Laboratório de Ensino e Fundamentos para o Estudo da Biodiversidade envolvidas na formação em temáticas ambientais. Em acordo com este primeiro resultado, encontramos em outra questão a indicação de uma visão dicotômica de EA segundo a qual os conhecimentos biológicos/ecológicos seriam mais relevantes e não necessariamente dialogariam com os pedagógicos. Nesse sentido, percebemos uma aproximação com a pesquisa de Giubbina e cols. (2008) uma vez que os futuros professores não ressaltam aspectos socioambientais em sua formação e com as conclusões de Silva e Carvalho (2012) que apontam para a ausência de uma visão de Ciência-Tecnologia-Sociedade-Ambiente integrada.

Com relação à futura atuação no magistério, a maioria dos licenciandos respondeu que se sentem preparados, devido à formação tida ao longo de sua graduação, para abordar temas de EA. Este resultado, em particular, contrapõe-se àquele obtido na pesquisa de Verona e Lorencini Jr. (2009) de acordo com a qual os futuros professores não se consideram aptos a trabalhar a EA em suas aulas por não terem tido uma formação consistente na universidade. Observamos ainda, de forma interessante, que os alunos atribuem papel fundamental à sua formação em serviço já que serão as práticas que eles terão ao exercerem o magistério que os capacitarão a se tornarem educadores ambientais. Isso demonstra que, apesar da maioria deles considerarem-se capacitados para abordar a EA na escola, vários compartilham da ideia de que a docência é construída cotidianamente no diálogo com questões particulares da comunidade escolar.

Nossos resultados sinalizam a necessidade de ser implementada nos cursos de Ciências Biológicas uma metodologia "integrada e interdisciplinar" em acordo com o que é apresentado no primeiro parágrafo do Art. 19 das Diretrizes Curriculares Nacionais para a Educação Ambiental (BRASIL, 2012). Acreditamos que ao abordar temáticas ambientais em disciplinas dos cursos de licenciatura de modo a contemplar questões sociais, históricas, culturais, além das científicas e tecnológicas contribuiremos para a formação de educadores com uma visão crítica de EA. Desta forma, o presente trabalho permite-nos compreender o cenário específico no qual os dados foram coletados, orientando futuras ações, bem como vem se somar as análises de pesquisas 
anteriores da área que têm apontado a urgência em retirar o foco do viés técnicocientífico que tem perpassado a formação em assuntos ambientais buscando uma compreensão de EA ampla, transformadora e crítica.

\section{Referências}

BRASIL. Lei 9.795 de 27 de abril de 1999. Política Nacional de Educação Ambiental. 1999.

CUNHA, A. M. de O.; CHIRIELEISON, E. e GUIDO, L. de F. E. Conhecendo a própria concepção de Educação Ambiental. In: Caderno de Programas e Resumos do X Encontro Perspectivas do Ensino de Biologia. Campinas, SP: FE/UNICAMP, 2006.

FREIRE, P. Pedagogia do Oprimido. 17. ed. Rio de Janeiro: Paz e Terra, 1987.

GIUBBINA, F, F.; CAMPOS, M. L. A. de M. e ABREU, D. G. de. A formação ambiental segundo a percepção de licenciandos em química. In: Anais do XIV Encontro Nacional de Ensino de Química. Curitiba: UFPR/SBQ, 2008. Disponível em http://www.quimica.ufpr.br/eduquim/eneq2008/resumos/R0730-1.pdf.

GUIMARÃES, J. de M. M.; ALVES, J. M. Formação de professores na área de Educação Ambiental: uma análise dos anais da ANPEd (2009-2011). Pesquisa em Educação Ambiental, vol. 7, n. 1, p. 49-66, 2012. Disponível em http://www.periodicos.rc.biblioteca.unesp.br/index.php/pesquisa/article/view/6786/4953

LIPAI, E. M.; LAYRARGUES, P. P. e PEDRO, V. V. Educação ambiental na escola: tá na lei... In: MELlO, S. S. de e TRAJBER, R. (Orgs.). Vamos cuidar do Brasil: conceitos e práticas em educação ambiental na escola. MEC/MMA: Unesco, 2007.

LOUREIRO, C. F. B. Sustentabilidade e educação: um olhar da ecologia política. São Paulo: Cortez, 2012.

LOUREIRO, C. F. B. e COSSÍO, M. F. B. Um olhar sobre a educação ambiental nas escolas: considerações iniciais sobre os resultados do projeto "O que fazem as escolas que dizem que fazem educação ambiental?”. In: MELLO, S. S. de e TRAJBER, R. (Orgs.). Vamos cuidar do Brasil: conceitos e práticas em educação ambiental na escola. MEC/MMA: Unesco, 2007.

SILVA, L. F. e CARVALHO, L. M. A temática ambiental e as diferentes compreensões dos professores de física em formação inicial. Ciência \& Educação, vol. 18, n. 2, p. 369-383, 2012. Disponível em: http://www.scielo.br/pdf/ciedu/v18n2/a09v18n2.pdf. 
Ensino, Saúde e Ambiente - V6 (3), pp. 96-113, dez. 2013

TRAJBER, R. e MENDONÇA, P. R. (Orgs.). Educação na diversidade: o que fazem as escolas que dizem que fazem educação ambiental. Brasília: Secretaria de Educação Continuada, Alfabetização e Diversidade, 2006.

VERONA, M. F. e LORENCINI JR, A. Concepções de Educação Ambiental e a Formação Inicial de Professores de Ciências e Biologia: uma análise da Universidade Estadual de Londrina (UEL/PR). In: Anais do V Encontro de Pesquisa em Educação Ambiental. São Carlos, SP: UFSCar, 2009. 